\title{
Limits to Subsurface Remediation: Is the Sky Blue or Obscured by Red Tape?
}

\author{
by Michael Barcelona
}

"Our technical

obstacles can only

be confronted by

properly designed

experiments."
$\mathrm{P}$ rofessionals in our field have become acquainted with limits, often painfully. There are well-defined limits to contamination site characterization, monitoring, and the potential alternatives for site cleanup and remediation. We can appreciate the difficulties associated with source identification, in particular, with delineating NAPL (non aqueous phase liquids: e.g., fuels, solvents) distributions. We now recognize that computational models applied to problems of flow, transport, and reactions are useful in improving site characterization efforts, monitoring network designs, and selecting useful plume containment options. Venting, sparging, pump and treat, and biologically enhanced variations on these themes may not be the whole answer to these problems, but they can be made to work. This can happen, despite the limits to our understanding of subsurface processes that affect contaminant stability, mobility, and potential exposures. For models to be totally diagnostic, site-specific inputs for rate limiting processes of desorption, mixing, and chemical and biological transformations must be available.

As an experimental scientist, the only answer that comes to mind is that the limits of our capabilities will be burst by passing through the "doors of perception."
William Blake, the British poet and scholar who coined this phrase, knew that only experiments can open these doors. He and other members of the Hellfire Club conducted chemical experiments of a social-technical nature. A similar route may be just the answer to our own limitation problems. The technical obstacles noted above may be confronted by properly designed experiments. Indeed, I think most of us have given serious thought to experimental designs in our own work. The social side merits further examination, since the current venues for in situ experimentation are few.

Consider the results of a recent survey of cleanup/remedial project managers associated with U.S. Navy installations. Most of the respondents had been in the field three years or more and over 80 percent were not currently using any alternative technologies to the standards of current practice (e.g., vacuum extraction, venting/ sparging, capping, excavation/incineration/treatment, barriers, or pump and treat).

A third of the respondents indicated that innovative or emerging technologies (i.e., those for which few or limited full-scale demonstrations had been conducted) were not planned in their prospective site cleanup options. The remainder suggested that 
these technologies were (or could be) planned at their site, though barriers existed to implementation.

This is the interesting part, folks. A full 91 percent of those considering the use of alternative technologies indicated that they did not have sufficient manpower or resources to study and select an innovative or emerging technology under their current work load. The other major related barriers to the use of new technologies (in decreasing order of importance) were:

- Regulatory acceptance;

- Time, oversight and command structures, and existing regulatory agreements put too much pressure on remediation decision making to meet action limits;

- Uncertain performance of (risk of failure) or unfamiliarity with, alternative/emerging technologies;

- Higher perceived costs for, or contracting difficulties with, the technologies; and
- Other reasons including insufficient site characterization and assessment data, and no leeway in ROD (Record of Decision).

To meet at least the major social barriers disclosed by the survey, it is clear that the experiments we might conduct must have both regulatory approval (at some level, preferably federal) and be welldocumented in field demonstration to be implemented at other sites. How can this be accomplished?

We clearly need to support the extension of efforts like the U.S. EPA's SITE (Superfund Innovative Evaluation), Department of Defense (DOD) ESTCP (Environmental Security Technology Certification Program), and the DOD/ National Environmental Technology Demonstration Program funded by SERDP (Strategic Environmental Research and Development Program) with EPA and DOE. These programs have been set up to promote and support the demonstration and evaluation of promising new technologies at fed- eral cleanup sites with regulatory assistance. These programs and others in the industrial and government sector represent the keys to the "doors of perception" through which both technical and social limits can be passed. For more information on the programs, consult an EPA Office of Solid Waste and Emergency Response publication EPA/542-B94-012, September 1994. The title is "Innovations of Hazardous Waste Treatment Techniques: A Developers Guide to Support Service". It can be ordered from U.S. EPA/NCEPI, P.O. Box 42419, Cincinnati, $\mathrm{OH} 45242-0419$ or fax: (513) 891-6685, (513) 891-6561 confirmation.

Dr. Michael J. Barcelona is with the Department of Civil \& Environmental Engineering, University of Michigan, Ann Arbor, Michigan. He is editor of Ground Water Monitoring \& Remediation.

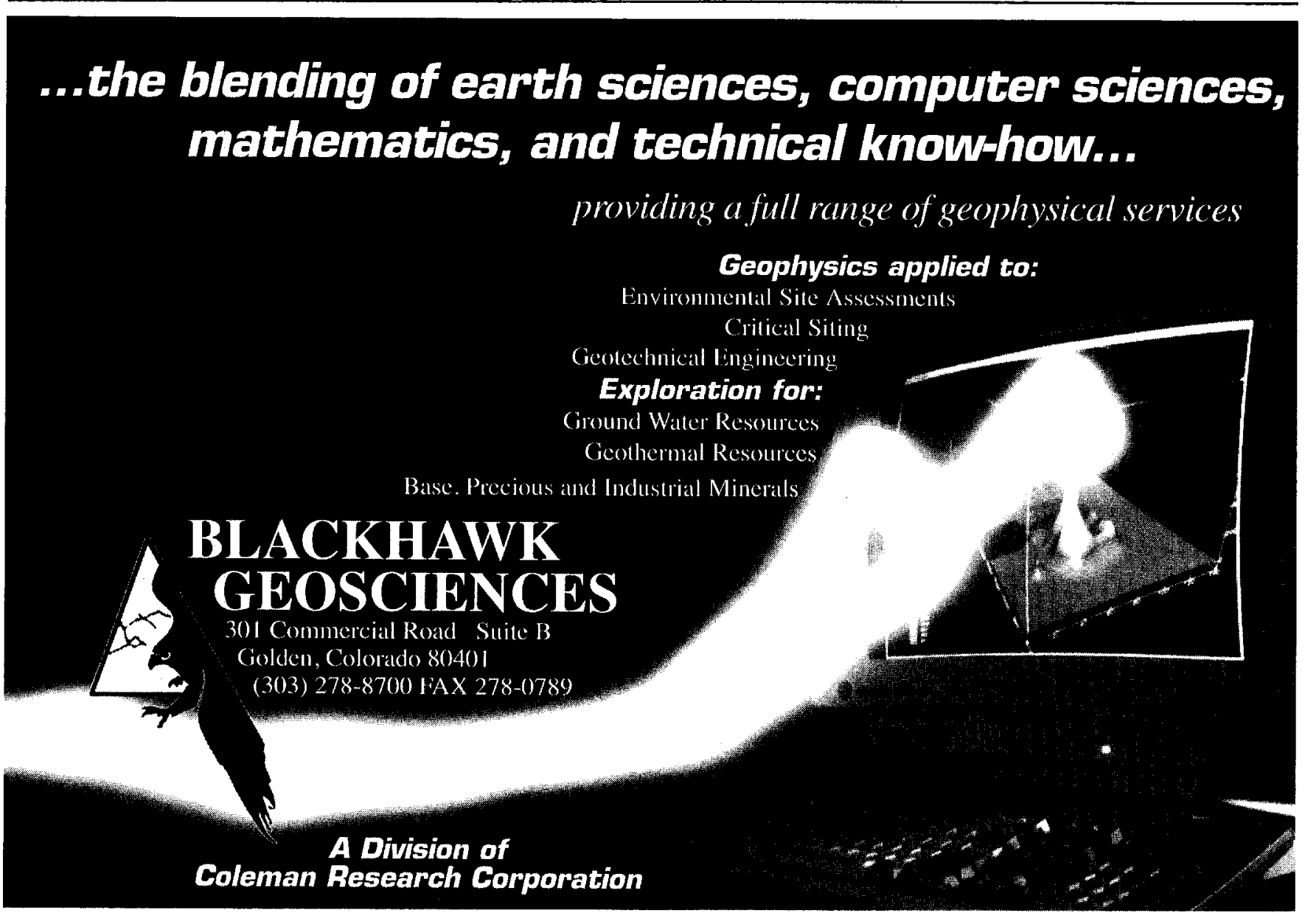

Circle card no. 9 